


\title{
TRANSGRESIONES CUBANAS: OFELIA RODRÍGUEZ ACOSTA Y LA MUJER/NACIÓN INDEPENDIENTE Y LÉSBICA
}

\author{
CUBAN TRANSGRESSIONS: OFELIA RODRÍGUEZ ACOSTA AND THE \\ INDEPENDENT AND LESBIAN WOMAN/NATION
}

Marisela Fleites-Lear

\begin{abstract}
RESUMEN
El ensayo examina tres de las novelas más importantes de la escritora cubana Ofelia Rodríguez Acosta (1902-1975) El triunfo de la débil presa (1925), La vida manda (1928), y Sonata interrumpida (1940). El análisis parte de la tesis de que estas obras son un reto a la imagen de la naciente nación cubana que desde los primeros momentos se basó en la idea de la familia heterosexual como la unidad social y económica central de la sociedad. Su reto abrió las puertas en Cuba desde la literatura para formular un ideal de la nación cubana que incluyese una pluralidad de género. Dado que el camino hacia ese ideal ha sido lento, tortuoso, e incompleto aun, el examen de la obra de esta autora pionera, silenciada en la Cuba revolucionaria hasta muy recientemente, tiene importancia crucial para reivindicar un pasado que puede dar más raíces a un futuro inclusivo. Palabras clave: Ofelia Rodríguez Acosta, feminismo cubano pre-1959, lo homoerótico en la literatura cubana, intersección género/nación en la literatura cubana, Cuba 1920-1940.
\end{abstract}

\begin{abstract}
This essay examines three of the most important novels of Cuban writer Ofelia Rodríguez Acosta (1902-1975) El triunfo de la débil presa (1925), La vida manda (1928), and Sonata interrumpida (1940). The analysis is based on the thesis that these works are a challenge to the image of the rising Cuban nation that from the first moments was based on the idea of the heterosexual family as the central social and economic unit of Cuban society. Her challenge opened the doors in Cuba from the realm of literature and journalism to formulate an ideal of the Cuban nation that included a gender plurality. Given that the road towards that ideal has been slow, tortuous, incomplete, the examination of the work of this pioneering author, silenced in the revolutionary Cuba until very recently, has crucial importance to claim a past that can provide more roots to an inclusive future. Keywords: Ofelia Rodríguez Acosta, Cuban Feminism pre-1959, homoeroticism in Cuban literature, Gender/nation intersection in Cuban literature, Cuba 1920-1940.
\end{abstract}

Dra. Marisela Fleites Lear. Green River College. Profesora de Español y Literatura. EstadosUnidos. Correo electrónico: mfleites@greenriver.edu

Recepción: 25-04- 2015

Aceptación: 22- 05- 2015 
En 1977 Vilma Espín, fundadora y presidenta vitalicia de la Federación de Mujeres Cubanas (FMC) afirmó:

\begin{abstract}
Nosotros nunca hemos tenido un movimiento feminista. Odiamos eso. Odiamos el movimiento feminista de los Estados Unidos... ;Vemos estos movimientos en los Estados Unidos que han concebido la lucha por la igualdad de la mujer contra los hombres!... ¡Esto es absurdo, no tiene sentido! ¡Que esas feministas digan que son revolucionarias es ridículo! (citada en Azicri, 1980, p. 115)
\end{abstract}

El pasado feminista cubano le fue negado a la generación de mujeres que nació después del triunfo de la revolución y sólo se ha ido reivindicando tímidamente dentro de la isla después de los años 90s, gracias a los cambios que poco a poco se han dado luego de la caída del campo socialista. Aun ya pasados 15 años del siglo XXI, la educación general pre-universitaria cubana no incluye ninguna referencia al movimiento feminista anterior a 1959 ni a la trascendencia continental que tuvieron muchas de sus exponentes. Las mujeres históricas que se celebran por el discurso oficial son mayormente aquellas que participaron como madres y enfermeras de los mambises que combatieron por la independencia contra España, y a las que apoyaron y formaron parte del movimiento 26 de julio que culminó con el triunfo revolucionario de 1959. De modo que "descubrir" la obra de Ofelia Rodríguez Acosta y de las líderes del movimiento feminista que desde principios del siglo XX lucharon por re-definir la nación cubana desde la perspectiva del género significó, en lo personal, una revelación iluminadora. Hay ya varios ensayos sobre Rodríguez Acosta, en particular los de Nina Menéndez, Zaida Capote Cruz y Elena M. de Jongh, aparte de análisis de su importancia y contribuciones en capítulos de textos que examinan a la mujer cubana en lo literario y lo político, como los de Catherine Davies y Lynn Stoner, y el del cubano Emilio Bejel en su importante obra Gay Cuban Nation, en la que examina la conexión del nacionalismo con la homofobia en la historia republicana cubana y el papel de algunas feministas como Ofelia en el rompimiento de ésta. El presente ensayo dialoga con estos autores y los toma como puntos de partida, pero dado que éstos se han concentrado principalmente en su novela La vida manda y/o su obra periodística, se enfatizarán las contribuciones de Ofelia en otros de sus escritos haciendo un análisis textual de los mismos para examinar cómo construye un ideal de nación desde el papel central de la mujer abriendo espacio en esta perspectiva a lo homo-erótico y lo homosexual como parte de ese ideal. ${ }^{1}$

Ofelia Rodríguez Acosta tuvo gran relevancia entre los años 1920-1940, cruciales en la formación del imaginario de la nacionalidad cubana, con sus novelas El triunfo de la débil presa (1925), La vida manda (1928), y Sonata interrumpida (1940), (entre otras), y con sus múltiples ensayos y crónicas de viaje. ${ }^{2}$ Nacida en Artemisa en 1902 fue una prolífica novelista, periodista (especialmente para Bohemia, donde tenía a su cargo una sección) y destacada activista feminista revolucionaria. ${ }^{3}$ Según Zaida Capote, Ofelia participó activamente en la lucha contra el dictador Gerardo Machado y se sabe que estuvo en la manifestación contra el asesinato del estudiante revolucionario Rafael Trejo en 1930 (2011, p. 2). Fundó y dirigió la revista Espartana en 1927 y fue bibliotecaria del Club Femenino de Cuba en 1925. Defendió en sus obras la teoría de la superioridad del amor libre frente a la moral católica, sostuvo la idea de que las tragedias de la mujer se debían a las normas sociales restrictivas de su libertad, abogó por la liberación de la mujer de la dependencia económica y social de los hombres, que debía empezar por la liberación de las mentes femeninas. Se le considera una feminista socialista (Stoner, 2003, pp. 97-102). Fue lo que en la época se consideraba como una mujer con "vida independiente," ya que nunca se casó y logró mantenerse económicamente por su trabajo como escritora dentro de la clase media alta cubana. Esta denominación en su época 
era un eufemismo para las mujeres que se sospechaban como lesbianas (Bejel, 2001, p. 47). Tuvo que luchar no sólo para defender sus ideales feministas, sino también para defenderse de lo que Ambrosio Fornet llama "la distribución sexista de "roles autorales" en la Cuba de ayer y de hoy, que la llevó en los años 40 a radicarse en México, al menos por un tiempo (1994, p. 71). De hecho, cuando recibió una prestigiosa beca del gobierno cubano que le permitió viajar por Europa como cronista/periodista y publicar sus crónicas en la revista cubana Grafo entre 1935 y 1937, ${ }^{4}$ muchos escritores masculinos como Jorge Rigol la ridiculizaron y la criticaron, considerándola una "mediocre intelectual" que no merecía tal beca (Capote, 2011, p. 6).

$\mathrm{Su}$ segunda novela, La vida manda, tuvo un gran éxito comercial. Sus dos ediciones se agotaron totalmente. Provocó intensos debates dentro del movimiento feminista cubano y a nivel del público general, por la crudeza casi agresiva con la que presenta la situación de la mujer en la Cuba entre le década de 1920 y 1930 (Capote, 2011, p. 19) y sobre todo por las críticas dentro de los grupos de derecha católicos que la tildaron de inmoral (Menéndez, 1997) y hasta de pornográfica (Capote, 2011, p. 20). La polémica sobre su vida y obra aún continúa, en particular porque hay muchos datos biográficos desconocidos, hasta el punto de que algunos autores como Lynn K. Stoner afirman que murió en México en un manicomio (2003, p. 143). Emilio Bejel por su parte informa que no se sabe si murió en México o en Cuba, pero que en cualquier caso murió en un asilo para enfermos mentales (2001, p. 48), cuando en realidad todo parece indicar que regresó a la isla después de 1959, tras haber vivido y trabajado en México desde los años 40 y murió en Cuba en 1975, en el Asilo Santovenia (EcuRed, 2011), un asilo de monjas para ancianos desamparados (pero no para enfermos mentales). ${ }^{5}$ De acuerdo con Zaida Capote, existe un certificado de defunción del hospital Dr. Salvador Allende en el que consta que murió de una bronconeumonía el 28 de junio de 1975 (2011, nota 1). No hay información sobre cuándo y cómo regresó a Cuba, ni sobre su opinión acerca de la revolución cubana. ${ }^{6}$ Es como si aún en la distancia, Ofelia se aferrase a mantener su independencia.

La reflexión sobre la multifacética y problemática relación entre la nación y el género dentro del contexto histórico cubano puede hacerse desde múltiples planos de análisis. Por ejemplo, es posible abordarlo desde el lugar históricamente asignado a las mujeres en el proceso (inacabado) de formación de la nación por aquellos que históricamente se han creído a la vanguardia de él. Otro ángulo podría ser el modo en que la imagen de la mujer ha sido históricamente manipulada dentro del discurso masculino oficialista para representar a la nación como estatua femenina llamada a ser esculpida por los denominados héroes viriles. Es posible también examinarlo en términos del modo en que las propias mujeres se han imaginado a sí mismas dentro de la nación y cómo la han conceptualizado y ficcionalizado. Es en este último sentido en el que puede calibrarse la contribución de Ofelia Rodríguez Acosta al imaginario de la nación cubana y de la identidad nacional.

Sus obras pueden leerse como un reto a la imagen de la naciente nación cubana que desde los primeros momentos se basó en la idea de la familia heterosexual como la unidad social y económica básica de la sociedad. Como señala K. Lynn Stoner, en la Cuba de principios del siglo XX, "La administración de bienes y la propiedad, la responsabilidad familiar, el estatus social y la influencia política, todas estas cuestiones se basaban en la organización y las reglas familiares." (2003, pp. 65-66). Las mujeres protagonistas de las novelas de Rodríguez Acosta desafían esta centralidad de la familia como núcleo de la nación, a través del rechazo al matrimonio tradicional, de la aceptación de la existencia de mujeres homosexuales exitosas, de la participación política independiente de la mujer, sobre todo en el contexto de la lucha 
contra la dictadura de Machado y por el sufragio femenino. Pueden considerarse sus obras como esfuerzos pioneros en el desarrollo de una novela explícitamente feminista en América Latina (Menéndez, 1997, p. 178). Como es característico de esta época en la literatura cubana, su estilo sigue el del realismo social con reminiscencias del modernismo en su lenguaje (sobre todo en la primera novela). Aunque no hay una gran experimentación formal, el lenguaje es muy detallista y en ocasiones muy sensual, combinando en todos los casos el diálogo con un narrador omnisciente, incorporando reflexiones filosóficas, sociológicas y de crítica literaria como parte de la trama, además de sueños y pesadillas. Hay alusiones a personajes de la política cubana de la época, descripciones de la ciudad de la Habana, de sus calles e incluso de sus barrios marginales, así como de las costumbres sociales tanto de los más pobres como de la clase media baja y alta.

$\mathrm{Su}$ primera novela El triunfo de la débil presa (escrita en 1925) está llena de comentarios, casi en forma de ensayos ensartados en la trama de ficción, sobre temas como la importancia del cultivo de un sistema de colaboración eficaz entre las mujeres; la comunicación entre padres e hijos como elemento central en la educación; la necesidad del divorcio $^{7}$ y la importancia de luchar contra los prejuicios morales que limitan las libertades femeninas. ${ }^{8}$ La obra promueve la "amistad profunda, entrañable, que no conciben los hombres entre las mujeres [...] en la que no sólo rige el deber sentimental [...] sino el placer intelectual..." (Rodríguez-Acosta, 1926, p. 49). Celebra así la amistad entre mujeres como fuente de agencia, abridora de caminos creativos. De cierta manera, la relación entre la protagonista y su prima Ernestina anuncia las relaciones homo-eróticas que aparecerán en sus novelas siguientes. Baste examinar el pasaje en que Ernestina, convaleciente de una enfermedad, es atendida por la protagonista Fabiola. ${ }^{9}$ Ernestina se queja con dolor de las limitaciones sociales que no le permiten realizarse como poeta, abre los ojos y mira a Fabiola:

\begin{abstract}
Aquella mirada no la había visto nunca Fabiola, ni en hombres ni en mujeres: era única como un secreto, era opaca y luminosa como una estrella cubierta por la gasa de una nube [...] Y eran las dos, en el reposo de la estancia, un mentís rotundo a la incrédula maldad de los hombres. Alguna vez se enfrentaron dos mujeres, libres de prevenciones, de rivalidad, y se dieron la mano con franqueza. Alguna vez harían ver a los satirizadores de sus sentimientos, que dos mujeres podían reunirse para algo que no era precisamente de modas y de figurines, de algo que tampoco era el orgiástico brindis de Afrodita [...] Fabiola y Ernestina se miraban al hablarse [...] (Rodríguez-Acosta, 1926, p. 49)
\end{abstract}

Como en casi todas sus obras, la autora está jugando con la ambigüedad genérica, tanto así que, para protegerse, tiene que aclarar que esas miradas no tenían "torcidas intenciones... [ni]... las repulsivas lubricidades de Louys."10 (Rodríguez-Acosta, 1926, p. 49). Incluso al final, luego que Fabiola está ya viviendo con su amante Ricardo y ha rehusado el matrimonio, Ernestina empieza a contarle la declaración de amor de su amigo Felipe: la introducción de su cuento conduce momentáneamente al lector a pensar que la sexualidad de Felipe es también ambivalente:

Ernestina, yo la amo a usted de un modo que no sé si usted podrá aceptar. ¿Me promete decirme con franqueza si le sería posible vivir conforme a él, sin exigirme otro, que desde ahora confieso honradamente, no poderle ofrecer nunca [...] se estrecharon las manos, cual dos hombres, cuyas palabras tienen por sí solas el valor de un juramento. (Rodríguez-Acosta, 1926, p. 105)

Esta obra usa la ficción casi como una excusa para ofrecer no sólo una descripción de la historia de la isla muy poética sino, y sobre todo, para reflexionar sobre el constante acecho a su existencia independiente. La nación se examina en su 
[...] drama eterno, su drama de hija natural: el rubio desaprensivo y adinerado quiere entrar en su alcoba, y al acercarse, los ojos de la India enrojecen, lanzan llamas, y como lagos muertos que de pronto rebosan sus aguas, por un misterio atmosférico, cierra sus párpados henchidos de llanto. (Rodríguez-Acosta, 1926, p. 31)

Cuba es "la india" siempre acechada por "el rubio": la historia nacional es alegóricamente ficcionalizada como la lucha constante contra la violación del cuerpo de la nativa por los poderes extranjeros y por los gobiernos corruptos que permiten que penetren en el cuerpo de la nativa. Este drama se disfraza y esconde anualmente en el Carnaval, mezcla de "locura, mentira, vértigo." (Rodríguez-Acosta, 1926, p. 37) Sin embargo, la "india violada" no se conforma con ser víctima, por el contrario "Sabe amar; sabe pensar; sabe leer y escribir. Activa, extiende su industria y su comercio; sentimental, crea su música; inteligente, desborda la savia de su cerebro en su rica y abundante literatura." (Rodríguez-Acosta, 1926, p. 31).

En esta obra tan temprana destaca un elemento realmente revolucionario: la autora se detiene a celebrar a una mujer negra, vendedora de tamales, que pregona por las calles de la Habana, a pesar de ostentar el cargo de General de las guerras de independencia contra España. La describe como:

\footnotetext{
[...] la morena vendedora, con zarandeo criollo de cintura, y el negro tabaco en la mano;[...], la morena brava que blandió el machete, que vio correr la sangre del mambí altivo, y unió sus fuegos al bélico ardor de los esclavos; la etiópica mujer que virilmente se mezcló a la epopeya redentora para forjar el triunfo de la libertad[...] [con] su histórico nombramiento de General [...]que ofreció su acción y su esfuerzo a aquella legión de cubanos invictos que nos dieron patria. (Rodríguez-Acosta, 1926, p. 14)
}

El reconocimiento de mujeres luchadoras por la independencia no ha sido típico de la historiografía oficial cubana donde el lugar de honor se le ha conferido sólo a los hombres. Desde la independencia y aun después de las revoluciones de 1933 y 1959, a un pueblo acostumbrado al asidero de las imágenes, se le ofrecieron sólo iconos libertadores masculinos para adorar. Aun en el discurso más liberal, incluso feminista y luego en el de la revolución de 1959, el espacio simbólico de la mujer siguió ocupado por su contenido Mariano, establecido por la tradición católica, pero re-creado en la veneración a Mariana Grajales como madre mambisa que en esencia socializa y conceptualiza a la mujer en primer término como madre protectora. ${ }^{11}$ Por el contrario, ya desde 1925 Ofelia nos ofrece otra iconografía donde no sólo da cabida a las mujeres independientes de la clase media, sino a personajes como esta tamalera cuya contribución a la independencia y el desarrollo de Cuba no le fue reconocida como era debido por su condición de mujer. Es una iconografía que renueva críticamente el discurso nacionalista de su época abriendo espacios para la mujer no-conformista en el futuro de la nación. En ella, la mujer que se celebra no es la madre sumisa sino la mujer que decide agarrar las riendas de su existencia. La protagonista de esta novela es de hecho crítica acérrima de su madre, por su sumisión callada a un esposo español déspota. El recuerdo de la voz de su madre, luego perpetuado en el de su tía "era la voz que la martirizaba desde que vino al mundo: la voz universal de la tradición, de la intransigencia, de los formulismos, eructando sobre el refinamiento de sus conceptos, la injuria y la maldición.” (Rodríguez-Acosta, 1926, p. 85). La voz de Fabiola se enfrenta constantemente a la voz "beoda de vicio clandestino y de abyecto hartazgo, su Majestad: la Consideración Social.” (Rodríguez-Acota, 1926, p. 86).

Es preciso entender la revolucionaria producción novelística de Ofelia Rodríguez Acosta en un momento donde las novelas y cuentos de muchos de sus contemporáneos son, o bien novelas rosa para consumo "femenino;" de gran circulación en toda América Latina; o 
bien la novela "seria", masculina, que centra su atención en personajes-héroes-hombres en lucha contra la naturaleza y la "barbarie" (como en De tierra adentro (1906) de Jesús Castellanos); o "haciendo la historia" (por ejemplo en La manigua sentimental (1910) de Jesús Castellanos o La insurrección (1910) de Luis Rodíguez Embil, ambas de marcado carácter costumbrista), o recreando a personajes masculinos en lucha por el poder (como Los inmorales (1918) de Carlos Lobería) o develando los misterios de las religiones afro-cubanas (Ecué-Yamba-O (1931) de A. Carpentier). A diferencia de sus contemporáneos masculinos, Ofelia Rodríguez se aproxima a la realidad social de las frustraciones con la distorsionada república cubana ${ }^{12}$ a través de mujeres que participan activamente en los cambios sociales y/o que desafían las normas morales imperantes. Todas aspiran y logran tener un "cuarto propio". Todas se insertan en la vida intelectual y política de su país. Todas reclaman un lugar dentro de una nación que las ha relegado siempre. La madre no aparece como el ideal unificador y estable en sus obras. De hecho, todas las personajes centrales son huérfanas y ninguna es madre (ni aun las que tienen biológicamente hijos): en El triunfo de la débil presa, la protagonista Fabiola pierde a su hija (se la quita su ex esposo) y no la ve nunca; en La vida manda, el bebé de la personaje central, Gertrudis, (que ha decidido tener soltera, con un "donante") muere a pocas horas de nacer; y en Sonata Interrumpida la protagonista Fernanda no se casa nunca ni tiene hijos, sus hijos son sus escritos, como periodista y novelista y su activismo dentro del movimiento feminista nacional. Discrepo así con la opinión de Lynn Stoner que incluye a Rodríguez Acosta en el grupo de las feministas que exaltan la maternidad y la función biológica de la mujer como principios para luchar por sus derechos (Stoner, 2003, p. 150).

Al explorar las diferencias entre sus textos y las voces masculinas de la época hay un elemento que no se ha trabajado en la literatura sobre esta autora y que merece destacarse. Su obra más famosa, La vida manda (1928), en cierto sentido sigue el modelo de La Garçonne, del autor francés Victor Margueritte, de amplia circulación en Cuba en esta época. Fue tal el impacto de esta obra, que de ahí viene el término "garzona" utilizado en Cuba para designar a las mujeres "liberadas" o poco "femeninas". En la novela de Margueritte, también traducida al inglés y con varias ediciones en EUA, el personaje central es una muchacha de la aristocracia que rechaza el matrimonio de conveniencia al que la empujan sus padres, logra independizarse económicamente cuando se va a vivir sola y se hace famosa como diseñadora de escenografías y de interiores, defendiendo su derecho al amor libre. Hay aquí, como en La vida manda, la insinuación de la posibilidad de una relación lesbiana. Pero lo que cabe destacar es la diferencia: al final de La Garçonna, Monique accede a casarse por amor. En cambio, en La vida manda, Gertrudis (el personaje central) nunca cede, decide incluso arreglar con un antiguo novio para quedar embarazada y tener un hijo soltera, pero al final el hijo muere, ella trata de suicidarse y queda ciega. La ceguera y la tragedia no aparecen como un castigo moral "bien merecido" por haber soliviantado las normas, sino como la imposibilidad para un solo individuo de cambiar las normas sociales: estuvo ciega al creer que podía ser independiente (Rodríguez-Acosta, 1930, p. 246).

Mientras Ofelia escribe su novela, La vida manda (1928) el presidente de turno, General Gerardo Machado, había logrado imponer una enmienda en la constitución cubana que le permitía re-elegirse, había desatado una represión creciente contra toda oposición y trataba de manipular el apoyo de los grupos sufragistas femeninos, los que a su vez se debatían en fuertes contradicciones con los grupos feministas que en su mayoría se manifestaban en contra de Machado y trataban de situar la lucha más allá de la consecución del voto femenino (González-Pagés, 2005, pp. 101-137). La autora estaba inmersa en este ambiente de activismo 
político, participó en los diferentes congresos nacionales de mujeres (1923 y 1925) y en múltiples reuniones y luchas de diferentes organizaciones femeninas y feministas. De hecho su alter ego, el personaje de Fernanda en su novela autobiográfica Sonata Interrumpida dedica su vida al periodismo feminista y a la lucha por las reivindicaciones más importantes de las feministas de su época porque "quería darse, plena, apasionadamente a los libros, a la amistad, al arte, a los humildes, a las mujeres postergadas, a la humanidad que sufre y trabaja." (Rodríguez-Acosta, 1943, p. 103).

Es extraordinario que en época tan temprana y dominada por un ambiente de opresión moral católica y de homofobia, el único personaje mujer independiente y exitoso de su novela La vida manda (1928) sea Delia, una mujer lesbiana en cuya casa se dan tertulias literarias a las que asiste lo más progresista de la intelectualidad habanera. De la misma forma, en Sonata Interrumpida hay otro personaje de éxito, Rosa, que claramente se declara como lesbiana. Coincido con Emilio Bejel cuando afirma:

\footnotetext{
It is Cuban feminism that opened a radical new perspective that not only benefited women's rights, but also questioned patriarchy and gender roles in general. In doing so it chose a new way to represent homosexuality. In fact, starting from the Cuban feminist movement of the 1920s and 1930s, one can perceive some degree of success in the creation of a discourse in which the homosexual's defense is not uncommon. (Bejel, 2001, p. 43)
}

Bejel considera que los discursos relacionados con las relaciones de género y los conceptos de la familia se daban en esta época bajo el marco general del nacionalismo "that is, all of them declare their principles and practices in the name of some sort of national morality." (2001, p. 44). ${ }^{13}$ Y aun cuando la base homofóbica del nacionalismo no se objetó nunca abiertamente, fueron las feministas las que lo retaron y cuestionaron de forma indirecta como parte de su reto directo al componente sexista del discurso nacionalista predominante. Esto se pone en evidencia, en particular, en la discusión pública entre la doctora Flora Díaz Parrado y la sufragista feminista Mariblanca Sabas Alomá. En ésta, la doctora afirma que el comportamiento lesbiano es preferible al de la mujer servil y que llegará un día en que la sociedad cambie sus ideas sobre el lesbianismo (citada en Bejel, 2001, p. 45). Es en este contexto en el que sobresale el tratamiento de la homosexualidad y del sexismo en la obra de Rodríguez Acosta. A diferencia de otras feministas, Ofelia es mucho más radical. Su feminismo distingue entre el sexo biológico y el género, sin condenar la sensualidad femenina en ninguna de sus formas, incluyendo la lésbica. Incluso en una novela más tardía de 1940, En la noche del mundo, dos de los personajes más importantes que viven juntos son dos hombres homosexuales, y su relación se presenta como un dechado de ternura, dedicación, apoyo y comprensión, más allá del deseo carnal sexual al que se reducía lo homosexual en la literatura positivista, naturalista y moralista de la época. ${ }^{14}$ Dado que su narrativa pretende insertarse en el proyecto de revolucionar la nación frustrada de su época, su inclusión con naturalidad de personajes positivos lesbianos y gays no deja lugar a dudas sobre el hecho de que Ofelia concibe su ideal de la nación cubana como aquél en el que una pluralidad de género tiene cabida.

La vida manda de 1928 ha sido analizada desde una lectura de género y Queer por varios académicos. Resaltan el estudio realizado por Nina Menéndez en su ensayo "Garzonas y feministas cubanas en la década del '20: La vida manda, por Ofelia Rodríguez Acosta” y el ya citado de Emilio Bejel. Coincidiendo en lo general con el análisis de estos críticos es preciso añadir algunos elementos que se relacionan con la construcción de un ideal de nación. El personaje de Delia, lesbiana y amiga de la protagonista Gertrudis, ${ }^{15}$ no solo no es condenado 
por ésta sino que, de hecho, aparece en sus momentos de crisis como tabla de salvación (excepto en su crisis final que termina trágicamente). La primera vez que se nos presenta a Delia es justo después que Gertrudis visita a su tía paterna y a sus primos, quienes viven en un barrio muy pobre, en condiciones muy precarias y promiscuas. Gertrudis tiene por costumbre ir a verlos prácticamente a diario, casi como una forma de auto-mortificación. En esta visita Gertrudis presencia la tragedia de esta familia de padre alcohólico, abusador, mujeriego y sifilítico, cuyos hijos y esposa viven en una pelea constante por la miseria, la falta de alternativas y la incomprensión (como gran parte de la nación cubana en esa época). Gertrudis se entera de que el hijo menor de dieciséis años, Félix, raquítico y enfermizo por la sífilis del padre, ha escuchado al padre de noche tratando de tener relaciones sexuales con su madre y a la madre que lo rechaza porque no quiere tener otro hijo enfermo como él. Gertrudis se siente impotente por “¡No poder lavarles el alma y los sentidos a todos!” (Rodríguez-Acosta, 1930, p. 34). Acto seguido conoce a Delia en la oficina de un amigo. En el intercambio que tiene Gertrudis con otro conocido que también está en la oficina, se revela como muy inteligente y capaz. Delia obviamente disfruta de las respuestas sagaces de Gertrudis, y ésta se siente halagada: "Delia rió, con risa fuerte y seca. Sus ojos brillaron. Gertrudis creyó leer en ese relampaguear, como sucede en los anuncios lumínicos intermitentes, una frase que se encendió y apagó en seguida [como pensando] «Es lista, la chica.»" (Rodríguez-Acosta, 1930, p. 36). El sentirse valorada por Delia envalentona a Gertrudis para seguir respondiéndole al conocido impertinente aun con más sagacidad. Este encuentro al parecer cancela los sentimientos de impotencia que había tenido antes al dejar a sus primos y que, de cierta manera, había sido anunciado por la voz narrativa cuando de camino a casa de los primos nos había dicho que Gertrudis esperaba con ansias "un encuentro con alguien, de algo sensacional que redimiera a sus ojos su vulgar existencia" (Rodríguez-Acosta, 1930, pp. 29-30).

La segunda vez que Delia aparece en la novela es justo después que Gertrudis ha tomado la decisión de romper su noviazgo formal confesándole a su comprometido que ama a otro a quien se ha "entregado" (Rodríguez-Acosta, 1930, p. 76). En una sociedad que valoraba la virginidad y el matrimonio como signos de decencia y destino de la mujer, la vida oculta de Gertrudis con su amante (cuyas relaciones sexuales apasionadas y sensuales se describen en la novela con un realismo inusual para la época), ${ }^{16}$ así como su decisión de romper un compromiso y aceptar el amor "prohibido" presentan una crisis para la protagonista. En esa situación busca de nuevo la compañía de Delia en la tertulia intelectual y artística que suele frecuentar. Después de que Gertrudis declara que no cree en la gratitud más que como resultado de la reflexión, ni en la amistad como sentimiento abstracto "Delia clavó sus ojos raros, hechos a las miradas más inexcrutables [sic], en la interlocutora de todos. Gertrudis se volvió a ella, con lento movimiento de cabeza, y recorrió con las suyas tranquilas la palidez momentánea en que parecían sumergirse los ojos de Delia” (Rodríguez-Acosta, 1930, p. 79). La obra explota el recurso de las miradas entre estas dos mujeres a lo largo de la novela, unas veces más elocuentes que otras, pero siempre indicando un subtexto que va más allá de la descripción narrativa. En el diálogo que sigue a ese intercambio de miradas Delia da muestras de conocer y pensar sobre Gertrudis más allá de lo que la novela nos ha dicho. Delia la defiende ante el círculo intelectual y vaticina su futuro trágico: “Gertrudis tiene una imaginación, un entusiasmo capaz de cualquier genialidad. Será por ello desgraciada. Sólo los cerebros de gran imaginación, de portentosa inventiva, aciertan y yerran en grande. Y esta alternativa es la fuente principal de su dolor" (Rodríguez-Acosta, 1930, p. 80). 
Lo que sigue es un diálogo muy íntimo entre ambas mujeres que sin embargo se está dando frente a un público masculino que se regodea en la escena. Delia confiesa que ha dedicado atención a lo mucho que Gertrudis calla, a lo que esconden sus silencios y los allí presentes reconocen que de todos, sólo Delia había tenido la capacidad de descubrir a la verdadera Gertrudis (Rodríguez-Acosta, 1930, pp. 81-82). Aunque hasta este momento no se ha dicho que Delia es lesbiana, la tensión textual transmite una fuerza a estos encuentros que no solo los torna en centrales a la trama aunque al parecer sean secundarios sino que también permiten al lector anticipar el homo-erotismo del que está cargada esta relación.

Una vez más aparece Delia justo después que Gertrudis tiene otro momento de gran crisis: su antiguo novio regresa de Santiago de Cuba, la golpea en plena calle porque cree que ella lo traicionó y, para colmo, Gertrudis se entera ese mismo día que su amante en realidad está casado. Después de una crisis de nervios que la paraliza, camino a su oficina se encuentra nuevamente con Delia en la calle. Delia le ofrece llevarla en su auto y Gertrudis acepta. De inmediato Delia reconoce que hay tristeza en Gertrudis. Delia le confiesa que la respeta, que la halaga ante otros en su ausencia y que desearía ser su amiga. Gertrudis teme al qué dirán si acepta su amistad. Hay un diálogo de silencios que podría pasar inadvertido para el lector que no esté atento. Gertrudis reconoce que ni evita ni busca a Delia y que ésta es demasiado gentil: "Cuando la veo, me interesa usted, Delia. Me agrada su conversación, por muchas cosas, una de ellas, porque halaga un poco mi vanidad... Vamos, porque me permite ser vanidosa, sin que ello llegue a constituir un delito." (Rodríguez-Acosta, 1930, p. 103) Este párrafo, que incluye los puntos suspensivos para indicar o bien la pausa en la conversación, o bien algo que el narrador omite, o bien un silencio, deja sentado que Gertrudis no rechaza a Delia. Acto seguido se pone en evidencia que Gertrudis sabe algo que no se formula pero que se deja entredicho: Gertrudis reconoce que se siente comprendida por Delia pero que si fuesen realmente amigas podría echarse a perder todo porque "usted sabe que yo sé quién es usted" (Rodríguez-Acosta, 1930, p. 104). Sin embargo, el saberlo no la lleva ni a la censura ni a compadecerla: "Sea usted como quiera y por lo que quiera" contesta Gertrudis, pues lo único que le interesa es el corazón de Delia, al que cree capaz de amar "en un sentido pagano, humano y divino" (1930, p. 104) pero no en el cuarto sentido, en el del amor absoluto, sin principio ni fin. Delia confiesa que Gertrudis está despertando este cuarto sentido en ella y en esto termina esta escena (1930, p. 105) separada de la siguiente por una serie de puntos suspensivos. Esta declaración se da dentro del auto de Delia y Gertrudis ni le pide que la deje bajarse ni se indigna por ella. De hecho, Delia es fuente de comprensión y es obvio que resulta un alivio a su situación angustiosa.

Hay otra personaje de sexualidad ambivalente en la novela a la que otros críticos no han prestado mucha atención: la prima Irene declara "No me puedo enamorar porque no me gustan los hombres" (Rodríguez-Acosta, 1930, p. 108) y, a pesar de esto, para Gertrudis "Irene era como una estrella sin cielo que rodara, dándose esquinazos, entre las sombras agobiadoras de su cuartucho." (Rodríguez-Acosta, 1930, p. 122). Lejos de condenarla la ama como prima, la comprende y la considera un ser puro dentro de tanta miseria. Esta prima ha sido molestada sexualmente por su hermano Juan, ha sido testigo del sexo entre sus padres y hacia el final de la novela es violada violentamente por un vecino, por lo cual Irene se suicida quemándose. ${ }^{17}$ Gertrudis reflexiona que la nación cubana es precisamente esa

[...] madeja de seres que envolvían el mundo, pululando en su superficie. Todo relacionado, todo afectado por la nada. Unas raíces que se tienden por debajo de las capas sociales y se nutren de su propio contacto y succión, sintonizando en el centro de la tierra. (Rodríguez-Acosta, 1930, p. 111) 
Así, en su concepto de nación todos están interconectados, no es posible excluir a unos y a otros dado que "la realidad total, [era el] substractum [sic] de las individualidades conglomeradas" (Rodríguez-Acosta, 1930, p. 111). El hecho de que Gertrudis encuentre refugio tanto en la tertulia donde se reúne una gama variopinta de la sociedad de clase media alta intelectual de la época y de cierta forma en sus visitas a la "cisterna" donde vivían sus primos como forma de comprender "más y mejor las miserias y los crímenes y los horrores de la humanidad, levantada sobre la frente sudorosa, tozuda, sufrida, de los pueblos nacidos a la manera vengativa, en medio de la floricultura de las civilizaciones" (Rodríguez-Acosta, 1930, p. 111) evidencia que para este personaje todos son parte integral de la nación y cualquier proyecto de cambio tendría que incluirlos en su interconexión. Es justo después de su encuentro con Delia primero y con Irene después que aparece la palabra feminismo: Gertrudis se declara a sí misma como un tipo de experimento, como si en ella la nación estuviese ensayando un nuevo camino de libertad sexual sin atadura de matrimonio, camino de independencia económica, dedicación al trabajo como una misión social y como fuente de emancipación (pp. 114-117).

Luego de la tragedia de la muerte de su prima Irene y su frustración con el amante que la engaña pero que la ata sexualmente, Gertrudis considera la posibilidad de irse a un convento y la desecha de inmediato porque no puede sujetarse a un canon artificial (1930, p. 136). De nuevo su refugio es su amistad con Delia y otros de la tertulia literaria, donde discuten de socialismo, comunismo, la relación del intelectual y las masas, el papel del arte en la sociedad, del matrimonio como arcaísmo, etc. Una vez más es Delia la que la caracteriza bien y la que la defiende frente a otros por ser

\footnotetext{
una mujer que trabaja, lucha, es pobre, y al mismo tiempo sabe pensar, está, de hecho, dentro del momento histórico. Una mujer que practica la libertad de amar, una mujer que es feminista, una mujer que no está afiliada a ninguna religión, es una mujer de la época. (Rodríguez-Acosta, 1930, p. 143)
}

De nuevo, en el momento de crisis que desata la tragedia final, cuando Gertrudis se entera de una nueva mentira de su amante, es Delia la que la apoya y la lleva en su automóvil al salir de la tertulia. Al verla sufrir, Delia le declara abiertamente su amor: "Yo nunca he amado a una mujer como a usted, hasta la renuncia, hasta la pureza de los sentidos, con estar los sentidos tan pendientes de ella...” (Rodríguez-Acosta, 1930, p. 147). Gertrudis la rechaza porque ha escogido un mal momento para declararle su amor y siente mucho tener que perder su amistad, pero no la censura moralmente, ni se horroriza de la declaración amorosa. De hecho es justo este rechazo lo que inicia el descenso de la protagonista hacia el final en que hace un intento suicida que la deja ciega. Sin embargo, aún hay un último pasaje muy sensual en el que Gertrudis está bebiendo en una fiesta y de nuevo la narración se regodea en un juego sensual de miradas elocuentes con Delia:

\footnotetext{
La mirada de Gertrudis, hipnotizada, bajó hasta los labios de Delia, que se estremecía voluptuosamente. Alocada, halló placer en aquella sensación nueva. ¿Qué honda y dolorosa caricia la de aquellos pérfidos y malévolos ojos fascinantes! También los suyos llegaron a mirar así. Se agitó, pecaminosamente en la larga, interminable, dulce mirada de la otra mujer. Delia sonreía triunfalmente. Esa sonrisa húmeda y palpitante, despertó a Gertrudis. Volvió en sí espantada. Se turbó desesperada, en medio de su caótica desorientación. (Rodríguez-Acosta, 1930, p. 194)
}

Al final de la fiesta, siente que alguien calma sus deseos físicos, pero no sabe quién es y se pregunta “¿Era Damián? ¿Felix? ¿Antonio? ¿Delia?” (Rodríguez-Acosta, 1930, p. 195). Su subconsciente embriagado da cabida a la posibilidad de que sea Delia quien la esté satisfaciendo sexualmente, y lo cierto es que ninguno de los otros en los que piensa están en 
esa fiesta. La mirada de Delia tiene el poder de desconcertarla, lo que más tarde recuerda como "el minuto de Delia" (p. 198). Al despertar se da cuenta de que está en la cama de Fonseca, su compañero de oficina y esto es la prueba de que "había caído" (p. 195). Empieza a vivir sin orientación, una vida solitaria. En su oficina se comenta que es amante de Fonseca, otros dicen que es amante de Delia. Decide que su única solución es tener un hijo para redimir su existencia de huérfana, su infancia desolada. Luego que muere el tío con el que vivía desde que había perdido a sus padres, Gertrudis le pide a su primer novio que le permita tener un hijo con él como donante. Piensa en la maternidad como forma de superación moral, de redención y lo único que resulta es que la dejan cesante en el trabajo por estar embarazada sin casarse, el padre biológico no quiere saber nada del embarazo y el niño muere cinco horas después de nacer. Ni la maternidad ni los hombres de su vida resultaron en una solución viable. En su crisis final no aparece Delia, no hay una puerta que se abra para dejarla repensar y recapacitar. El desenlace es pues, trágico.

Los críticos no han prestado atención al personaje de Rosa en Sonata Interrumpida. Rosa es una de las hijas de la familia de clase media que recoge a la protagonista, Fernanda, luego que la madre adoptiva de ésta muere. Rosa se dedica casi con desmesura al estudio del piano, y "poseía una pulsación verdaderamente viril” (Rodríguez-Acosta, 1943, p. 110). A Rosa, "jamás se le vio ninguna inclinación especial hacia alguno de los jóvenes que había conocido" (p. 110). En cambio su pasión por Elena, su maestra de piano, viuda, por la que siente un afecto "casi sordo, atormentado" (p. 95) es obviamente lésbica: "Sabía que habría de llegar el día en que, visitándola, entraría en su intimidad” (p. 110). En la búsqueda de esa intimidad,

\footnotetext{
Rosa revelábase de pronto irresistiblemente seductora... su boca carnosa, irregular, un poco dura, daban un vigor y a la vez una gracia a su fisonomía, según aflorase a ella los diversos y contradictorios movimientos de su alma, fascinadores. Fernanda preguntábase en ocasiones si todo aquel derroche de atracción no era de voluntaria provocación, no eran debidos a un sutil y refinado interés. Lo que ya no podía discernir era a cuál de las dos dirigía su atención. Intuía que Rosa misma habría de encontrarse en un trance muy difícil, si se le hiciese la pregunta. (Rodríguez-Acosta, 1943, p. 178)
}

Con la misma pasión con la que Rosa se dedica al piano y a su maestra, Fernanda, su cuasi-hermana adoptiva se dedica al movimiento feminista y a luchar contra el modelo de masculinidad patriarcal imperante. Para ella el feminismo ofrecía "doctrinas justas y nobles y luchar por la emancipación de la mujer era una causa digna a la que había que dar todas sus fuerzas, toda su actividad." (Rodríguez-Acosta, 1943, p. 96). Descubría en la actitud de los hombres que la rodeaban, incluso entre los miembros de la familia que la había acogido por ser huérfana y a los que amaba profundamente, "un principio de masculinidad, arbitrariamente agresiva, al que ellos obedecían por tradición. Contra esa inicua tradición había que luchar con denuedo; porque había muchas mujeres que sufrían bajo su yugo.” (pp. 96-97). Al igual que en El triunfo de la débil presa, en esta mujer independiente y decidida a luchar por sus derechos se da una conexión alegórica a través del cuerpo de la protagonista: se despierta al deseo sexual en el mismo momento en que la nación "se despierta" políticamente para defender la dependencia de la isla de los EE.UU. contra el imperialismo yanqui, abriendo el camino hacia la Revolución del 33: cuerpo/nación en transición. La novela hace coincidir la iniciación de Fernanda en la vida sexual con su primer amante con el momento en que los EEUU deciden en 1925 devolverle a Cuba la Isla de Pinos. Fernanda se rebela contra el agradecimiento a EE.UU. por el gesto, critica la politiquería y discute la supeditación de la isla al poder estadounidense al que según ella no hay que agradecerle nada porque "¿qué le debemos? La Enmienda Platt a nuestra constitución, sin cuya aceptación forzosa jamás se hubiese hecho 
en 1902 la transmisión de poderes de ellos a los cubanos. Hipotecados para toda la vida por nuestra gratitud eterna." (Rodríguez-Acosta, 1943, p. 117). Empieza a involucrarse en la lucha política contra la corrupción, contra los virajes de la política del presidente Gerardo Machado y en la crítica al intervencionismo estadounidense, en la misma medida en que se independiza económicamente, empieza a escribir para un periódico, se muda sola a un hotel y "se despierta a la vida" (p. 121) haciendo el amor por placer y puro gusto con un amigo pintor.

La novela va tejiendo la evolución de la vida de Fernanda como feminista siempre siguiendo la madeja de su relación con Rosa, aparentemente colateral (como antes lo hizo con el personaje de Delia y la protagonista en La vida manda.) En la convivencia diaria, en la presencia de Rosa y Elena, Fernanda va sintiendo una "lamentable enemistad que le venía de Rosa.” (Rodríguez-Acosta, 1943, p. 102). La trama juega con ese roce aparente entre los dos personajes. Fernanda, quien ha crecido al lado de Rosa, no puede entender la actitud contradictoria de aquella, el por qué por momentos la rechaza y otras le da muestras de extrema atención, como cuando decide tocar, en su primer concierto público, la Sonata Appassionata de Bethoven, la preferida de Fernanda. 18 "Rosa parecía siempre como si no supiese qué era lo que debía amar, qué era lo que debía odiar. Quién sabe si, después de todo, la música no fuese más que un refugio de su naturaleza... oscura.” (Rodríguez-Acosta, 1943, p. 106). Una vez más la narración juega con los puntos suspensivos para generar en el lector la duda de la raíz de esa oscuridad. Los puntos suspensivos sin embargo puede llenarlos el lector avezado a través de la compleja relación de Rosa y su maestra Elena, de sus esfuerzos por convertirse en el centro de la vida de Elena (p. 145), sus celos por la atención que aquella tiene que prestarle a su hijo (quien tiene un fuerte trastorno de la personalidad), y su asco ante "la cochina cosa" que ha hecho que su hermana Mónica esté embarazada y tenga que parir (p. 152). Por su parte Fernanda en varios momentos tiene también sentimientos contradictorios hacia Rosa como cuando tras una mirada de Rosa, con ojos "cargados de sombras" expresión de un abismo lleno de un "caos de emociones" Fernanda "sentíase, sin saber discernir la causa, hondamente turbada por aquellos ojos magníficos: tan bellos y enigmáticos.” (p. 152) De nuevo nos encontramos con una ficción cargada de ambivalencia genérica.

Al igual que Delia, quien aparece en la vida de Gertrudis en momentos de crisis, es Rosa la que responde a Fernanda en el momento más difícil de una crisis: Fernanda es perseguida por la policía del dictador Gerardo Machado por sus actividades políticas y sus escritos en un periódico clandestino para denunciar la corrupción y los abusos del gobierno. No puede regresar a su casa y a la única persona que llama es a Rosa. Inmediatamente ésta responde y viene a buscarla. Mientras discuten dónde podría esconderse, Fernanda confiesa que no tiene muchos amigos de confianza, ni siquiera su amante. Rosa "sufrió el hostigamiento de unos celos vehementes: casi físicos, casi feroces, que le avergonzaban un poco, hundiéndola en un caos de confusiones." (Rodríguez-Acosta, 1943, p. 178). Pero no dejó traslucir ni sus celos ni su confusión y decide pedirle a su maestra Elena que le dé refugio a Fernanda. Esta la esconde y gracias a eso Fernanda se salva de la suerte que corrieron sus otros compañeros que o bien fueron asesinados, o presos, o heridos por las mujeres de la porra. ${ }^{19}$ De modo que frente a la nación masculinizada, católica y homofóbica representada por el dictador, la mujer lésbica se vuelve la única opción de protección y escape.

Hacia el final de la novela se devela el misterio de Rosa, quien ya es una concertista reconocida, casada con el hombre del cual Fernanda estaba enamorada. Rosa se da cuenta al final, con dolor y desesperación reconoce ante Fernanda que en realidad toda su vida la había amado y sólo se daba cuenta después de tantos años: "Ahora lo sé... No era a Elena... no es 
a él... Es a ti a quien quiero... a quien siempre he querido.” (Rodríguez-Acosta, 1943, p. 296). Como en el caso de La vida manda, la protagonista no censura moralmente a Rosa. De hecho, Fernanda comienza a analizar su vida usando el lenguaje musical, la analiza como si fuera una Sonata, cosa que era típica del modo de hablar de Rosa. Como si su declaración de amor le hubiera dado permiso para asumir su lógica de razonamiento y sus metáforas musicales. En las últimas páginas el actual esposo de Rosa, amigo y amado por Fernanda, le escribe una carta a ésta declarándole también su amor. Lo curioso es que lo hace prácticamente copiando a Rosa: "Ahora lo sé, no es a ella a quien quiero,... a quien siempre he querido es a ti." (Rodríguez-Acosta, 1943, p. 803). Este paralelismo denota que la narración no hace distinción entre una forma de amor y la otra, las pone en el mismo plano. La tragedia no es que Rosa haya al fin descubierto que es lesbiana, sino que su esposo Jaime ame a la misma mujer y no quiera ocasionarle disgustos a su esposa. No hay acusación moralista, no hay negación de la legitimidad de Rosa. Su amor y su tragedia personal son también parte del entramado de la vida que no hay que eliminar.

Por último es importante referirse a otro personaje que valientemente la narración rescata y valora positivamente: Como periodista, la protagonista Fernanda va a cubrir los estragos del horrible ciclón de 1932 que generó un ras de mar que destruyó el poblado de Santa Cruz. ${ }^{20}$ La novela dedica página y media a honrar a una mujer "de la vida alegre (...) ruda, audaz, un poco masculinizada," "mujer "de la mala vida" (Rodríguez-Acosta, 1943, p. 205) gracias a la cual se salvaron muchos y se recuperaron los cuerpos de otros. Su actuación se califica como de un "heroísmo inaudito" (p. 204). En un momento dado esta prostituta del pueblo logra montarse en un caballo desbocado y lo usa para ir rescatando gente cual

\footnotetext{
[...] amazona heroica sobre su corcel en pelo, ramalazo de luz y esperanza que surcaba la tormenta con los brazos y el corazón en alto. Todos tenían fe en ella, como un ángel de la guarda, como una especie de dios mitológico: hacia ella levantaban su horror, su grito, su confianza. Y no sólo los que podían morir, sino los otros: los que clamaban por los suyos. (Rodríguez-Acosta, 1943, p. 205)
}

Desde las páginas de Bohemia, con su artículo semanal en la columna "Campaña Feminista", ${ }^{21}$ así como en sus múltiples ensayos, artículos periodísticos, crónicas, novelas, el feminismo revolucionario de Ofelia Rodríguez la hizo batallar constantemente por reconocer el papel que las mujeres debían tener dentro de la nación cubana, no sólo para aquellas blancas de clase media alta, sino para todas, desde la mujer negra General de las luchas independentistas vendedora de tamales, hasta la prostituta heroica que casi sola salva a medio pueblo, hasta la secretaria de una oficina pública, la joven abusada de un barrio marginal, la mujer revolucionaria que se involucra en las luchas anti-dictatoriales, las mujeres lesbianas, entre otras. Como expresa Zaida Capote todas estas mujeres luchan por ocupar un espacio propio, no sólo en el terreno político y en la tribuna pública sino también

\footnotetext{
[...] en el terreno del eros y la sexualidad, en el control de la natalidad, en el espacio íntimo y secreto de esos cuerpos de mujer [...] Mentes libres que deben habitar cuerpos supliciados, cuerpos donde también la negociación de la identidad nacional queda trunca, irresuelta, en suspenso, a la espera de otros cambios en el porvenir. (Capote-Cuz, 2011, pp. 20-21)
}

La escritora Ofelia Rodríguez no se sentó a esperar los cambios, fue, en su accionar y en su producción intelectual una luchadora incansable por lograr las transformaciones que permitieran liberar y reunir creadoramente las mentes y los cuerpos de todas las mujeres cubanas.

Hoy, como antes, se libran importantes batallas políticas en defensa de intereses nacionales desde el cuerpo de la mujer: Baste mencionar la centralidad en la política 
estadounidense de las cuestiones relativas al aborto y el constante uso de la violación sexual de la mujer como estrategia en muchos conflictos políticos, militares y étnicos. No es de extrañar entonces que las novelistas latinoamericanas se sigan cuestionando el concepto de nación históricamente defendido por el discurso hegemónico patriarcal, ni que lo hagan desde la reflexión sobre el cuerpo femenino como locus de intersección entre el género como constructo socio-histórico, la discriminación racial y las injusticias sociales. El cuerpo al parecer atrapado en los sistemas patriarcales/neocoloniales contra los que lucha, se resiste a la vez a la fijación y clausura: en él lo único constante es el cambio y la fluidez (Adjarian, 2004, p. 188).

Al examinar la escritura de mujeres desde comienzos del siglo XX éstas han llamado la atención hacia el carácter de ficción inestable de "lo nacional", al enfatizar los conflictos básicos y las contradicciones no resueltas en términos de la relación entre ciudadanía y sexismo (Kaplan, Alarcón y Moallem, 1999, p. 6), ubicando a éstos como una encrucijada que devela los vacíos e incongruencias de las estructuras patriarcales nacionales, inaprensible a través de las utopías grandiosas de la nación como algo estable, hecho y merecido. Como afirma Elena Poniatowska, el espacio reclamado por las mujeres escritoras en América Latina es precisamente el del nexo entre la exploración del significado y el conocimiento con el acto de protesta contra la injusticia. La mujer escribe para prestar testimonio, como un acto de insurrección (en Castro-Klaren, 1991, p. 22). En esta rebelión las escritoras utilizan diversas estrategias narrativas caracterizadas por la innovación formal que no distingue entre sueños, espiritualidad, realidad empírica y que rechaza la narrativa lineal combinando diferentes estilos escriturales que dan entrada en los textos a una multiplicidad de voces. En esta práctica desordenan los tropos dominantes de "lo apropiado". Con esto desacralizan y desmitifican símbolos históricamente asociados con el cuerpo femenino, rebelándose contra el lugar que se le ha asignado dentro del imaginario de la identidad nacional, como lo permanente y puro, la madre/tierra que abriga/siempre dispuesta/a ser gobernada: al cuestionar la división entre las esferas públicas y privadas se muestra cómo los vacíos y las contradicciones que plagan los disímiles proyectos nacionales inacabados, fragmentados, cada vez más contradictorios y llenos de injusticias se cosechan y "se cocinan" en el cuerpo y el espacio de la mujer. La obra de Ofelia Rodríguez abrió el camino a las mujeres cubanas y latinoamericanas para repensarse dentro de la nación no sólo como madres de héroes, sino como mujeres libres de amar y de contribuir a la transformación radical de la misma desde una pluralidad genérica que desacraliza lo oficialmente asignado como "femenino," desata la sensualidad de la mujer de cuerdas atávicas y le permite un lugar a la mujer lesbiana dentro de la madeja socio-histórica que construye y constituye lo nacional como ideal socio-histórico.

\section{Notas}

1. La crítica María del Mar López Cabrales celebra el hecho de que en la narrativa cubana a partir de los años 90 aparezca el tratamiento de lo lésbico y lo homoerótico, pero desconoce que hay un precedente crucial en la obra de Ofelia Rodríguez Acosta. Por eso no es correcta su afirmación de que "se puede encuadrar la escritura de Ena Lucía Portela como primera escritora cubana que abiertamente expresa en sus escritos la experiencia lesbiana" (2005, p. 75).

2. Entre su vasta bibliografía se encuentran también Evocaciones (crónicas) (La Habana, 1922); Dolientes (La Habana, Hermes, 1931); La tragedia social de la mujer (La Habana, Editorial Génesis, 1932); En la noche del mundo (La Habana, La Verónica, 1940); Europa era así. Crónica de viaje (México, D.F. Eds. Botas, 1941); La dama del arcón (México, Eds. Estela, 1949); Diez mandamientos cívicos (cinco éticos y cinco estéticos) (La Habana, Imp. Barandiarán, 1951); Hágase la luz. La novela de un filósofo 
existencialista. (México, Impresora Galvez, 1953); La muerte pura de Martí (México, Imprenta de F. F. Franco, 1955); Algunos cuentos (de ayer y de hoy) (México, B. Costa Amic, 1957); etc. (ver EcuRed). En el sitio de la red "Hojas de prensa para la historia de Cuba" dedicado a esta autora pueden leerse recortes de periódico de la época que nos dan una idea de su trascendencia (ver http://hojassdeprensa.blogspot. com/2012/01/ofelia-rodriguez-acosta-1902-1975-una.html).

3. Resulta inexplicable que haya sido ignorada en Cuba por tantos años. Por ejemplo, en la obra de Ana Nuñez Machín Mujeres en el periodismo cubano, probablemente la primera en Cuba que examina la contribución periodística de las mujeres cubanas, no se menciona a Ofelia Rodríguez Acosta, pero sí a Ofelia Domínguez Navarro y a Mariblanca Sabas Alomá, contemporáneas suyas. Estas últimas se quedaron en Cuba trabajando dentro del proceso revolucionario iniciado en 1959 y es lógico sospechar que sea ésta la razón por la que Nuñez Machín las incluye (a pesar de que Ofelia Rodríguez fue en algunos aspectos más radical).

4. Estos escritos se recogieron luego en su libro de crónicas Europa era así, publicado en México en 1941 por ediciones Botas. Para un análisis de algunas de sus crónicas ver el ensayo de Zaida Capote Cruz "Cubanas en España: Ofelia Rodríguez Acosta y Dulce María Loynaz".

5. Ver http://semanarioaccion.com/asilo-santovenia/

6. Una de las sobrinas de Ofelia explica que la conoció en Cuba en 1966 y que Ofelia vivía en la Habana Vieja en ese entonces. Esta sobrina emigró a los EUA y en el año 2000 regresó a Cuba para tratar de encontrar sus raíces paternas. Inició una pesquisa en un blog de genealogía que puede leerse en este sitio: http://www.genealogy.com/forum/regional/countries/topics/cuba/871/

7. Que se había legalizado en Cuba en 1918 pero aún se criticaba por una población mayormente católica.

8. Bien mirada esta novela, en las primeras 60 páginas no ocurre realmente nada significativo en términos de la trama de la ficción. Son páginas de disquisiciones filosóficas, políticas, morales y hasta costumbristas sobre Cuba, la nación, su historia y la discriminación de la mujer dentro de ella. La obra incluye asimismo lecturas críticas de la literatura en boga en su época, desde La rebelión de los ángeles, de Anatole France, Duelo a muerte de Eduardo Zamacois hasta Muerte de Jesús de Eça de Queiroz, entre otras que analizan sus personajes.

9. Cuyo nombre, del Latin (cosechadora de habas) se asocia con la emotividad, sensitividad, la pasión. "Su origen deviene de la antigüedad, la familia patricia romana Gens Fabia en el siglo V antes de Cristo, era muy poderosa y sus miembros del clan o tribu ocupaban puestos en el consulado; se enfrentaron a los patricios en defensa de los plebeyos por lo que casi se extinguen" (Euroresidentes, s.f., párr. 2). La Santa Fabiola supuestamente planteó el problema del divorcio en la sociedad romana, se divorció por la ley romana y luego de convertirse al cristianismo y de la muerte de su segundo esposo "dedica su vida a obras de caridad, funda hospitales como el de Ostia, atiende personalmente a los enfermos y viaja llevando la fe de Cristo" (Euroresidentes, s.f., párr. 3).

10. Pierre Louÿs (1870-1925) fue un escritor y poeta francés famoso por el uso de temas clásicos y sobre lesbianas. Buscó expresar la sensualidad pagana con perfección estilística. (Wikipedia).

11. Ver mi ensayo “iMi cielo, alcánzame las botas!: Feminismos, Mujeres y el ‘Hombre Nuevo’ dentro de la revolución cubana".

12. "De la revolución magna del 95, que fundió la libertad con el bronce de las voluntades de aquellos esclavos libertos, nos queda solo como prestigio, la honrosa bandera; como enfermedad: el generalato crónico" (Rodríguez-Acosta, 1926, p. 129).

13. Para una cronología del tratamiento al homosexual en Cuba ver Cronología TransCuba (1571-2011).

14. Ver la obra de Emilio Bejel al respecto, capítulo tres.

15. Nina Menéndez discute con el significado de escoger éste como el nombre de la protagonista en clara referencia o bien a la cubana Gertrudis Gómez de Avellaneda, conocida por su defensa de la mujer independiente, o bien a Gertrude Stein, de cuyo trabajo posiblemente Ofelia tuviera noticia, pero esto no puede probarse.

16. En esto discrepo de la opinión de Lynn Stoner quien afirma que a pesar de todo el alboroto sobre lo pornográfico de esta novela, no hay en realidad una descripción explícita de un encuentro sexual (2003, p. 141). Baste leer este pasaje, uno de muchos, en el que se describe un encuentro sexual entre Gertrudis y su amante: "Damián le mordisqueaba el glóbulo de las orejas [...] Y para él no había escondrijo en el 
cuerpo de la mujer que no hubiera osculado su boca, bajo la cual Gertrudis gemía, consumiéndose en un deseo insaciable, implacable, lleno de la neurosis de la forzada virginidad de sus años mozos. - Abre los ojos, quiero verte en ellos la felicidad que te doy. Ella abría los ojos, rasgadas las pupilas por la creciente palpitación de sus entrañas invadidas. Abría la boca, suspirante, reseca. Abría los brazos, cuyas manos quemantes bajaban y subían por la espalda de Damián, comprimiéndole contra sí." (Rodríguez-Acosta, 1930, p. 73).

17. Por cierto, en el pasaje de la violación, sumamente crudo, denuncia de la violencia de género, Gertrudis deja abierta la posibilidad del aborto, cosa inaudita en 1928. Ante la preocupación de Irene de salir embarazada del hombre que la violó, Gertrudis le contesta: “-Mira, Irene; si no quieres tener un hijo, no lo tendrás, ¡ea!" (Rodríguez-Acosta, 1930, p. 127). El tema del aborto se retoma sin juzgarlo de inmoral en su novela Sonata interrumpida cuando un personaje central se enferma tras hacerse ella misma un aborto (1943, p. 280).

18. Lo cual explica el título de la novela.

19. Como en el caso de Luisa a quien las mujeres de la porra o "porristas" le cortaron la cara de una cuchillada (Rodríguez-Acosta, 1943, p. 188).

20. La autora Ofelia Rodríguez de hecho fue enviada por el periódico en el que trabajaba en Cuba a este poblado y su crónica de los horrores que vio por el ras de mar se publicó en Bohemia (Capote, 2011, p. 2).

21. Esta columna "consistió en la publicación de un artículo semanal de Ofelia Rodríguez Acosta acerca del feminismo en su multiplicidad de aspectos... La campaña se inició con una encuesta, exclusiva para mujeres, a dos preguntas: ¿Cuáles son los principales defectos que impiden a la mujer un completo triunfo en la vida y en la causa feminista? Y ¿Cuáles son las virtudes y buenas cualidades que posee la mujer y que permanecen inactivas, retardando ese triunfo... La campaña feminista de Bohemia duró un total de dos años y tres meses y consistió en 78 ensayos periodísticos, una entrevista a Gabriela Mistral y el cuento titulado "La construcción de un hijo"”, (De-Jongh, 1995, p. 6).

\section{Bibliografía}

Adjarian, M. M. (2004). Allegories of Desire. Body, Nation and Empire in Modern Caribbean Literature by Women. Westport: Praeger Publishers.

Azicri, M. (1980). Cuba: Politics, Economics and Society. New York: Pinter Publishers.

Bejel, E. (2001). Gay Cuban Nation. Chicago: University of Chicago Press.

Capote-Cruz, Z. (2011). Escritores olvidados de la República: Ofelia Rodríguez Acosta. Fundación Alejo Carpentier. http://www.fundacioncarpentier.cult.cu/ [Consulta 20 abril de 2015].

Capote-Cruz, Z. (2012). Cubanas en España: Ofelia Rodríguez Acosta y Dulce María Loynaz. La Jiribilla. 10, 1-9. http://www.lajiribilla.cu/ [Consulta 3 marzo de 2015].

Castro-Klarén, S., Molloy, S. y Sarlo, B. (Eds.). (1991). Women's Writing in Latin America. Boulder: Westview Press.

Davies, C. (1997). A Place in the Sun? Women Writers in Twentieth-Century Cuba. London \& New Jersey: Zed Books Ltd.

De-Jongh, E. M. (1995). Feminismo y periodismo en la Cuba republicana: Ofelia Rodríguez Acosta y la campaña feminista de "Bohemia" (1930-1932). Confluencia. 11 (1), 3-12.

EcuRed. (2011). Ofelia de la Concepción Rodríguez Acosta García. http://www.ecured. cu/index.php/Ofelia_de_la_Concepci\%C3\%B3n_Rodr\%C3\%ADguez_Acosta_ Garc\%C3\%ADa [Consulta 2 de abril de 2015]. 
Euroresidentes. (s.f.) Significado del Nombre Fabiola. http://www.euroresidentes.com/ significado-nombre/f/fabiola.htm [Consulta 2 abril de 2015].

Fleites-Lear, M. (2008). ¡Mi cielo, alcánzame las botas!: Feminismos, Mujeres y el 'Hombre Nuevo' dentro de la revolución cubana. Journal of Iberian and Latin American Research. 14 (1), 49-77.

Fornet, A. (1994). Las máscaras del tiempo en la novela de la revolución cubana. Revista de Crítica Literaria Latinoamericana. 20 (39), 61-79.

González-Pagés, J. C. (2005). En busca de un espacio: Historia de mujeres en Cuba. La Habana: Editorial Ciencias Sociales.

Hojas de prensa para la historia de Cuba. (s.f.). http://hojassdeprensa.blogspot.com/2012/01/ ofelia-rodriguez-acosta-1902-1975/ [Consulta 3 abril de 2015].

Kaplan, C., Alarcón, N. y Moallem, M. (1999). Between Woman and Nation. Nationalisms, Transnational Feminisms, and the State. Durham y London: Duke UP.

López-Cabrales, M. del M. (2005). Desde las entrañas del deseo homoerótico en Cuba. Ena Lucía Portela y Karla Suárez. Confluencia. 20 (2), 74-82.

Margueritte, V. (1972). La Garçonne. Paris: J'Ai Lu.

Menéndez, N. (1997). Garzonas y feministas in Cuban Women's Writing of the 1920s: La vida manda by Ofelia Rodríguez Acosta. Por D. Balderston y D. J. Guy (Eds.). Sex and Sexuality in Latin America. (174-190). New York: NYU Press.

Nuñez-Machín, A. (1989). Mujeres en el periodismo cubano. Santiago de Cuba: Editorial Oriente.

Ramírez, M. M. (2010). Cronología TransCuba (1571-2011). https://transcuba.wordpress.com/ [Consulta 14 abril de 2015].

Rodríguez-Acosta, O. (1926) El triunfo de la débil presa. La Habana: Rambla, Bouza y Cia.

Rodríguez-Acosta, O. (1930). La vida manda. Madrid: Editorial Biblioteca Rubén Darío.

Rodríguez-Acosta, O. (1940). En la noche del mundo. La Habana: La Verónica.

Rodríguez-Acosta, O. (1943). Sonata interrumpida. México, D.F.: Ediciones Minerva.

Stoner, K. L. (2003). De la casa a la calle. El movimiento cubano de la mujer en favor de la reforma legal (1898-1940). Madrid: Editorial Colibrí.

Wikipedia: the Free Encyclopedia. (s. f.). Pierre Loü̈s. https://es.wikipedia.org/wiki/Pierre_ Lou\%C3\%BFs [Consulta 10 de mayo de 2015]. 
